\section{D) Check for updates}

Cite this: Dalton Trans., 2020, 49 12319

Received 15th April 2020,

Accepted 30th July 2020

DOI: $10.1039 / \mathrm{d} 0 \mathrm{dt} 01385 \mathrm{~d}$

rsc.li/dalton

\title{
A water-soluble bithiophene with increased photoluminescence efficiency and metal recognition ability $\dagger$
}

\author{
Estefanía Delgado-Pinar, (D) * Marta Pineiro (D) and J. Sérgio Seixas de Melo (D)
}

A new water-soluble tri-tert-butyl-bithiophenesulfonamide ( $\boldsymbol{\alpha 2}$-tbS) was synthesized and a comprehensive spectroscopic and photophysical study was undertaken in organic solvents and water at different $\mathrm{pH}$ values. In contrast to the behaviour found for the parent (and un-substituted) $\alpha, \alpha^{\prime}$-bithiophene ( $\boldsymbol{\alpha} \mathbf{2}$ ), in which radiationless decay processes are the main excited-state deactivation channels, the tert-butylsulfonamide derivative presents a significant fluorescence quantum yield $\left(\phi_{F}\right)$ ( $c a$. one order of magnitude higher than that of $\boldsymbol{\alpha} \mathbf{2}$ ). The high $\phi_{\mathrm{F}}$ allowed further exploring $\boldsymbol{\alpha} \mathbf{2}$-tbS as a selective fluorimetric sensor for metal ions. A strong selectivity towards $\mathrm{Cu}(\mathrm{I})$ is observed at neutral $\mathrm{pH}$ values, whereas at $\mathrm{pH}=9.5 \mathrm{a}$ strong quenching upon the addition of $\mathrm{Hg}(॥)$ is observed. An additional high sensitivity of $0.64 \pm$ $0.02 \mathrm{ppm}$ towards $\mathrm{Cu}(॥)$ was observed, well below $1.25 \mathrm{ppm}(\sim 20 \mu \mathrm{M})$, the maximum value allowed in drinking water by the EPA.

\section{Introduction}

Fluorescent materials with high selectivity and sensitivity to metal ions and anions and other elements that may have an environmental impact play an essential role not only in fundamental biology, pathophysiology, in clinical diagnosis and therapy ${ }^{1-3}$ but also in materials science with the development of stimuli-responsive molecules for the fabrication of smart materials. ${ }^{4-6}$ Thiophene-based oligomers and polymers have attracted remarkable attention as organic materials showing semiconducting, fluorescent, nonlinear optical and liquid crystalline properties. All these features can be fine-tuned through minor structural modifications. As a consequence, thiophene oligomers and polymers are among the most investigated compounds for applications in organic electronics, optoelectronics, and thin film devices such as field effect transistors, light emitting diodes, and photovoltaic devices. ${ }^{7,8}$

Among all these applications of thiophene oligomers and polymers, a further application as fluorescent sensors is explored. Actually, it is well-known that heavy metal ions such as $\mathrm{Hg}^{2+},{ }^{2} \mathrm{Cd}^{2+},{ }^{10} \mathrm{~Pb}^{2+},{ }^{11}$ and $\mathrm{Cu}^{2+}$ (ref. 12 ) can easily bind with proteins, enzymes, and nucleic acids, which may cause changes in the biological functions of these substances.

University of Coimbra, CQC, Department of Chemistry, Rua Larga, 3004-535, Coimbra, Portugal. E-mail: edelgado@qui.uc.pt

$\dagger$ Electronic supplementary information (ESI) available: NMR of the new compounds and absorbance and emission spectra of a2-tbS under different conditions: solvent, $\mathrm{pH}$ and metal addition. See DOI: 10.1039/D0DT01385D
Furthermore, there is growing evidence that copper and copper-binding proteins are common denominators in the mechanisms of neurodegenerative diseases such as Alzheimer's and Parkinson's. ${ }^{13,14}$ According to the National Primary Drinking Water Regulations of USA, the acceptable amount of copper ions in drinking water is $1.25 \mathrm{mg} \mathrm{L}^{-1}$ $(\sim 20 \mu \mathrm{M}),{ }^{15}$ beyond which they can cause cellular damage and Alzheimer's and Wilson's diseases. Therefore, low-cost on-site detector chips that can offer quantitative real-time detection of copper ions with identifiable signals (based on fluorescence) are clearly relevant. A low-cost methodology to rapidly detect these cations with sufficient sensitivity, but most importantly, in aqueous media is therefore mandatory.

However, the remarkable opto-electronic properties of conjugated thiophenes such as their high quantum yield are only possible with an oligomerization degree higher than six, which introduces some drawbacks: ${ }^{16}$ (i) their relatively low solubility in a wide range of solvents ${ }^{17}$ and (ii) the high mobility of the thiophene-thiophene bond, which allows twisted conformations that can limit conjugation through the oligothiophene chain.

Indeed, some efforts have been made in order to synthesize soluble bithiophene or terthiophene derivatives in polar or aqueous solvents without losing their photophysical properties for sensing applications. For example, by the introduction of side acyclic polyamine chains, a water-soluble bithiophene able to form stable copper complexes was developed by GarcíaEspaña et al. ${ }^{18}$ Functionalization of bithiophene units with propylenic and/or ethylenic chains containing protonated 
amines promotes a decrease in the $\pi-\pi$ stacking of the aromatic moieties by introducing electrostatic repulsive interactions between the positive charges present in the chains.

Although the synthesis of water-soluble bithiophene was accomplished, again some drawbacks can appear since a remarkable $\mathrm{pH}$ dependence is present in these derivatives: (i) the solubility of the compounds change depending on the $\mathrm{pH}$ value; (ii) some coordination with metal ions present in the media is also possible and, finally, (iii) the photophysical properties change depending on the protonation state of the amine groups. Other functional groups can be used for solubilizing polythiophenes, e.g. by attaching flexible pendant groups onto the conjugated backbone. ${ }^{19}$ However, almost all of them are charged groups that, once more, show $\mathrm{pH}$ dependence. Moreover, a work on a novel oligothiophene-phenylamine-based Schiff base as a dual fluorescent chemosensor for the detection of $\mathrm{Hg}^{2+}$ and $\mathrm{Cu}^{2+}$ ions has been reported recently; yet, the solubility of this sensor in water is very low. ${ }^{20}$

Finally, the importance of solubilizing this fluorescent unit in water is based on its application as a synthetic precursor for biologically active compounds active against the acute phase of African trypanosomiasis ${ }^{21,22}$ or interact with multi-stranded DNA structures. $^{23,24}$

A new strategy, developed in this work, consists of the incorporation of sulfonamide groups into the bithiophene backbone. The $\mathrm{SO}_{2}$ group is a strong electron acceptor that converts the amine into a very weak acid. Furthermore, the sulfonamide group is not a simple solubilizing agent and also the $-\mathrm{SO}_{2} \mathrm{NH}$ - group can play a role in the future application of the ligand since sulfonamide occurs in numerous biologically active compounds, which include antimicrobial drugs, saluretics, carbonic anhydrase inhibitors, antithyroid agents, and a number of others. ${ }^{25}$

For this reason, here we present the synthesis of a new water soluble bithiophene derivative, and most interestingly, showing an improvement in the fluorescence emission in comparison with its parent compound. The acid-base behaviour is also evaluated over a wide $\mathrm{pH}$ range and the coordination of different transition metals is studied. All these improvements pave the way for a new line of research consisting of the development of a new family of stable compounds with high solubility in water and good fluorescence response for various applications including metal sensing.

\section{Results and discussion}

\section{Synthesis}

Scheme 1 depicts the procedure for the synthesis of the 3,5,5'(tert-butyl)sulfonamidebithiophene derivative, $\boldsymbol{\alpha 2}$-tbS. Very briefly, chlorosulfonation of bithiophene through electrophilic aromatic substitution with neat chlorosulfonic acid at $0{ }^{\circ} \mathrm{C}$ for $24 \mathrm{~h}$ gives the trisulfonyl chloride derivative as a dark brown solid in almost quantitative yield. Posterior reaction under microwave irradiation with a primary amine allows the syn-

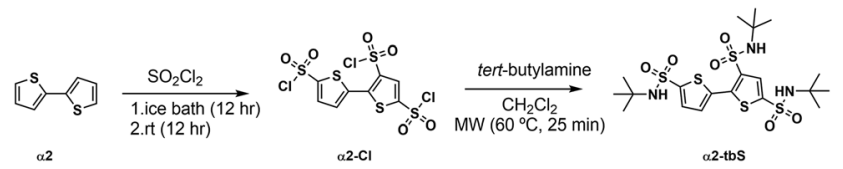

Scheme 1 Schematic synthetic route for the synthesis of the trisulfonamide derivative.

thesis of the trisulfonamide derivative tri-tert-butylsulfonamide ( $\boldsymbol{\alpha 2}$-tbS).

The chlorosulfonation of aromatic systems has been successfully used for the synthesis of water-soluble derivatives, sulfonamides and sulfonic acids, of several aromatic compounds. $^{26,27}$ Molecular orbital calculations of bithiophenes indicated that the order of reactivity with electrophiles is $\mathrm{C}-5>\mathrm{C}-3>\mathrm{C}-4^{28}$ and experimentally, by controlling the stoichiometry of the reaction, it was possible to obtain $5,5^{\prime}$-disubstituted- or 3,3',5,5'-tetrasubstituted bithiophenes selectively. ${ }^{29}$ Therefore, by performing the reaction under neat conditions with an excess of chlorosulfonic acid, the expected product is the tetrasubstituted derivative. The NMR spectra of the product of chlorosulfonation reaction performed in an ice bath for 12 hours and then 12 hours more at room temperature gave a distinct pattern of trisubstituted derivatives with three signals (two doublets and one singlet) with an integration ratio of $1: 1: 1$. The substitution of hydrogen by sulfonyl groups with electron withdrawing character will decrease the rate of the electrophilic aromatic substitution, increasing the deactivation of the bithiophene with the increase of the degree of substitution, which could be responsible for the formation of the trisubstituted derivative as the major product and the absence of the tetrasubstituted bithiophene even under the neat conditions used. The full characterization of the trisulfonamide derivative, obtained by reaction with tertbutylamine under microwave irradiation with $70 \%$ yield, allows confirming the position of the substituents in the bithiophene ring. Together with the signal at higher magnetic field assigned to the tert-butyl and $\mathrm{NH}$ hydrogen, the ${ }^{1} \mathrm{H}-\mathrm{NMR}$ spectrum shows three signals in the aromatic region, two doublets at $7.50 \mathrm{ppm}$ and $7.65 \mathrm{ppm}$ and a singlet at $7.95 \mathrm{ppm}$ with a relative integration ratio of $1: 1: 1$ (Fig. $\mathrm{S} 4 \dagger$ ). The ${ }^{13} \mathrm{C}$ spectrum shows ten signals, at 30.0 and 47.1 ppm corresponding to the aliphatic groups; at 129.2, 130.1, and $131.3 \mathrm{ppm}$ corresponding to the $\mathrm{C}$ of the aromatic structure bearing one $\mathrm{H}$ atom; at 136.5 and $137.0 \mathrm{ppm}$ corresponding to the carbons in the bridge of the two thiophene units; and finally at $141.2,145.7$, and $149.5 \mathrm{ppm}$ corresponding to the $\mathrm{C}$ of the aromatic structure bearing the tert-butyl group (Fig. S5 $\dagger$ ). The bidimensional HMBC spectrum shows a correlation between the hydrogen of the disubstituted thiophene ring (the singlet in the ${ }^{1} \mathrm{H} \mathrm{NMR}$ ) and only one of the quaternary carbons of the $2-2^{\prime}$ linker, which should be the nearest, indicating that the other carbon of the linker is at least at four bond distance which is only possible with substitutions at positions 3 and 5 of the thiophene ring (Scheme 2 and 


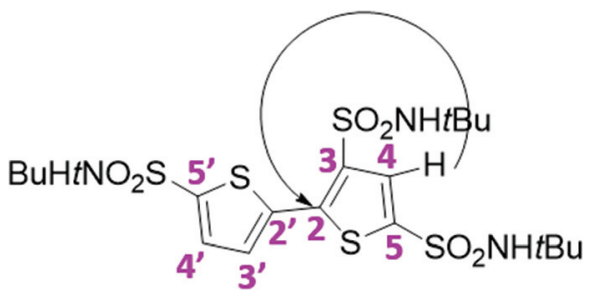

Scheme 2 Nomenclature used in the attribution of the NMR signals of $\alpha 2$-tbS.

Fig. S6 $\dagger$ ). Therefore, the singlet in the ${ }^{1} \mathrm{H}$ NMR is attributed to the $\mathrm{H}$ at position 4 .

\section{Absorption and fluorescence}

The absorption and fluorescence emission spectra of the tri(tert-butylsulfonamide)bithiophene, $\boldsymbol{\alpha 2}$-tbS, and the unsubstituted bithiophene, $\boldsymbol{\alpha} 2$, in dioxane are shown in Fig. 1 and the data of the other solvents of different viscosities and dielectric constants are summarized in Table 1. In general, the absorption and emission spectra of $\boldsymbol{\alpha} \mathbf{2}$-tbS display the characteristic spectroscopic features of the parent oligothiophene (with a

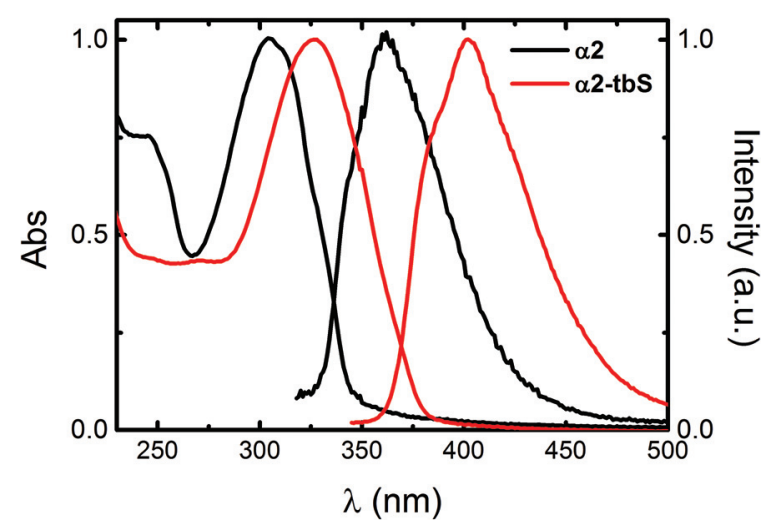

Fig. 1 Normalized absorption and fluorescence emission spectra of $\alpha 2$-tbS (red) and $\alpha 2$ (black) in dioxane at $T=293 \mathrm{~K}$.

Table 1 Spectral data (including absorption, $\lambda_{\text {absi }}$ excitation $\lambda_{\text {ex }}$; and emission, $\lambda_{\text {em }}$ wavelength maxima; Stokes shifts) of $\alpha 2$ and $\alpha 2-\mathrm{tbS}$ at $T=$ $293 \mathrm{~K}$

\begin{tabular}{|c|c|c|c|c|c|c|}
\hline Compound & Solvent & $\begin{array}{l}\eta \\
(\mathrm{cP})\end{array}$ & $\begin{array}{l}\varepsilon \\
\left(\times 10^{3} \mathrm{M}^{-1} \mathrm{~cm}^{-1}\right)\end{array}$ & $\begin{array}{l}\lambda_{\max }^{\mathrm{Abs}} \\
(\mathrm{nm})\end{array}$ & $\begin{array}{l}\lambda_{\max }^{\text {Fluo }} \\
\text { (nm) }\end{array}$ & $\begin{array}{l}\Delta_{\mathrm{SS}} \\
\left(\mathrm{cm}^{-1}\right)\end{array}$ \\
\hline \multirow[t]{3}{*}{$\alpha 2$} & Dx & 1.439 & 2.2 & 306 & 361 & 4979 \\
\hline & DMF & 0.924 & 36.7 & 305 & 363 & 5239 \\
\hline & $\mathrm{MeOH}$ & 0.593 & 32.7 & 302 & 358 & 5180 \\
\hline \multirow[t]{7}{*}{$\alpha 2$-tbS } & Dx & 1.439 & 2.2 & 326 & 403 & 5861 \\
\hline & DMF & 0.924 & 36.7 & 332 & 402 & 5245 \\
\hline & $\mathrm{MeOH}$ & 0.593 & 32.7 & 323 & 401 & 6022 \\
\hline & 2MeTHF & 0.575 & 7.6 & 328 & 402 & 5612 \\
\hline & $\mathrm{H}_{2} \mathrm{O}$ pH 0.4 & 1.009 & 80.2 & 313 & 403 & 7135 \\
\hline & $\mathrm{H}_{2} \mathrm{O}$ pH 6.6 & & & 316 & 403 & 6972 \\
\hline & $\mathrm{H}_{2} \mathrm{O} \mathrm{pH}$ & & & 323 & 402 & 5612 \\
\hline
\end{tabular}

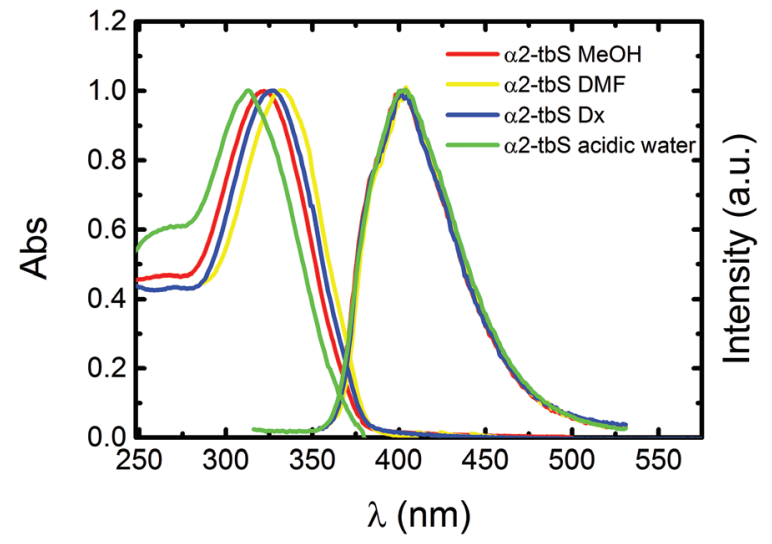

Fig. 2 Normalized absorption and fluorescence emission spectra in dioxane (blue), methanol (red), dimethylformamide (yellow), and water at acidic $\mathrm{pH}=0.4$ (green) solutions at $T=293 \mathrm{~K}$.

broad absorption band-lacking vibronic structure-and a more structured fluorescence emission, see Fig. 1).

The characteristics of the absorption and emission spectra of $\boldsymbol{\alpha} \mathbf{2}$ are the result of the existence of different conformations in the ground state (the spectra mirror the ensemble of conformers with different dihedral angles between the two thiophene rings) and of a more planar and rigid quinoidal-type trans-conformation in the excited state. ${ }^{30}$ Although a similar spectral behaviour is found for $\boldsymbol{\alpha} \mathbf{2}$-tbS, some interesting different features are worthy of note. Indeed, $\boldsymbol{\alpha 2}$-tbS exhibits large spectral solvent dependent red-shifts of the absorption (20-27 nm) and emission wavelength maxima (39-43 $\mathrm{nm}$ ) when compared to $\boldsymbol{\alpha 2}$ (see Table 1), thus pointing to an increase in the $\pi$-electronic delocalization in the former. The identical characteristic absorption and emission spectra, together with the similar Stokes shift values $\left(\Delta_{\mathrm{SS}}\right)$ of $\boldsymbol{\alpha} 2$ (Table 1 ), point to the identical structural changes in the ground and excited states for $\boldsymbol{\alpha 2}$-tbS and $\boldsymbol{\alpha} 2$.

Fig. 2 shows the absorbance and emission spectra in both aprotic and protic organic solvents of different polarities (representative solvents are shown in Fig. 2; for more solvents, see Fig. S8 $\dagger$ ), together with the absorbance in water at different $\mathrm{pH}$ values (Fig. S9). $\uparrow$ A red-shift with the increase in the polarity of the media was observed in the absorption spectra whereas no observable change in the fluorescence was found. These results point out once again for a quinoidal-like structure in the excited state of $\boldsymbol{\alpha 2} \mathbf{2}$-tbS and absence of intramolecular charge transfer transitions.

\section{Dependence on $\mathrm{pH}$}

As mentioned in the introduction section, despite the high number of applications of oligothiophenes as fluorescent sensors, their use in biological media is often hampered by their low solubility in aqueous or polar solvents. However, with the present tert-butylsulfonamide derivatization in the bithiophene moiety, a significant improvement in the solubility in water was obtained, which allowed the study of the spectroscopic and photophysical properties of $\boldsymbol{\alpha} 2$-tbS in a wide $\mathrm{pH}$ 
a)
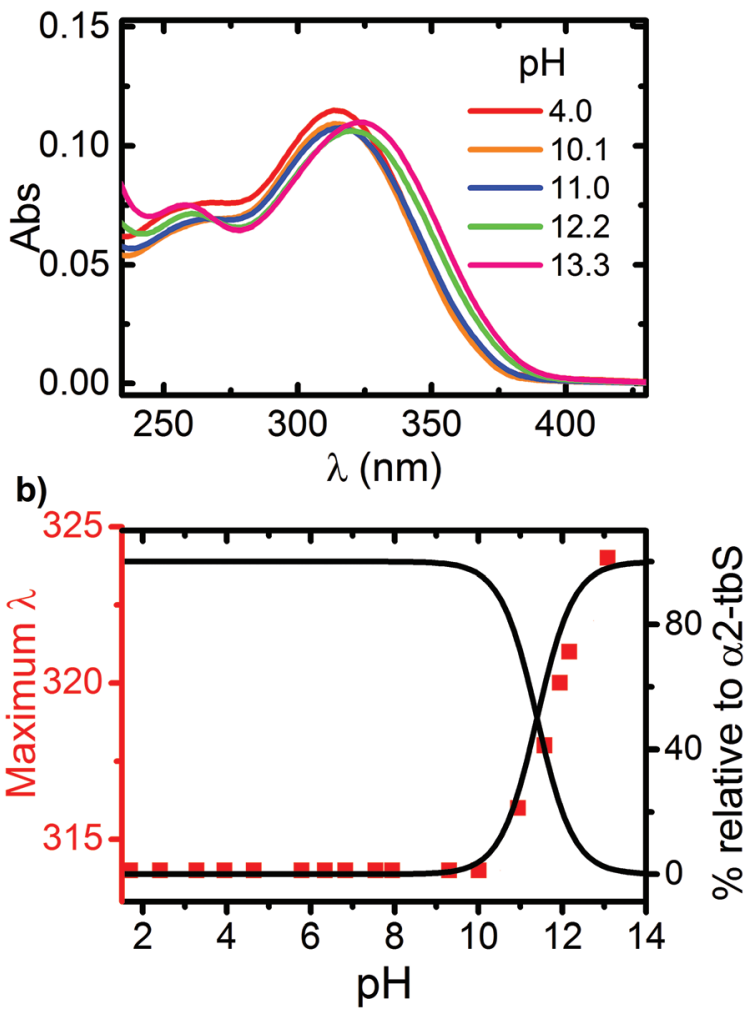

Fig. 3 (a) Absorption spectra of $\alpha 2$-tbS recorded at $T=298 \mathrm{~K}$ in water as function of $\mathrm{pH}$; (b) absorption maximum wavelength ( $\square$ ) and mole fraction distribution curves (\% relative to $\alpha 2$-tbS) as functions of $\mathrm{pH}$ for the different protonated forms (solid lines).

range. Fig. 3 shows the absorption spectra as a function of the $\mathrm{pH}$ together with the corresponding titration curve (for the complete titration curve, please see Fig. S9†). The acid-base equilibrium in the ground state involves the presence of a neutral ( $\boldsymbol{\alpha 2}$-tbS) and a tri-deprotonated species $\left(\boldsymbol{\alpha} 2\right.$-tbS ${ }^{3-}$ ) (see Scheme 3) with absorption maxima at $313 \mathrm{~nm}$ and $323 \mathrm{~nm}$, respectively. From the spectrophotometric titration (Fig. 3b), a $\mathrm{p} \beta_{13}$ - defined as the cumulative constant of the tri-deprotonation of $\boldsymbol{\alpha 2}$-tbS (see supplementary data for equilibria equations, Scheme S1) $\uparrow$-value of around 11.4 was obtained when the wavelength absorption maximum was plotted versus the $\mathrm{pH}$. Indeed, secondary sulfonamides (without electronwithdrawing groups on nitrogen) are considered relatively acidic $\left(\mathrm{p} K_{\mathrm{a}} \sim 10\right)$ because the charge formed in the conjugate base can be stabilized by resonance. ${ }^{31}$

From the fluorescence emission titration (Fig. 4a), the characteristic emission of the neutral form of $\boldsymbol{\alpha} 2$-tbS is observed with a strong decrease in the fluorescence intensity with the pH. At very basic $\mathrm{pH}$ values (see inset), a blue shift in the emission band is also observed. The gradual decrease in the fluorescence emission with the $\mathrm{pH}$ increase (see Fig. 4a and Table 2) is a consequence of the competitive quenching (electron transfer) promoted by the unprotonated sulfonamide groups. Furthermore, the emissive spectral changes can be quantitatively obtained from the fluorescent quantum yield

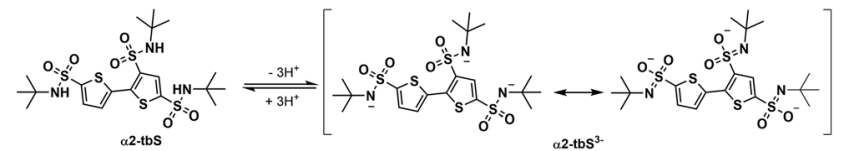

Scheme 3 Acid-base equilibria for $\alpha 2$-tbS together with the proposed resonant structures for the tri-deprotonated form.

a)

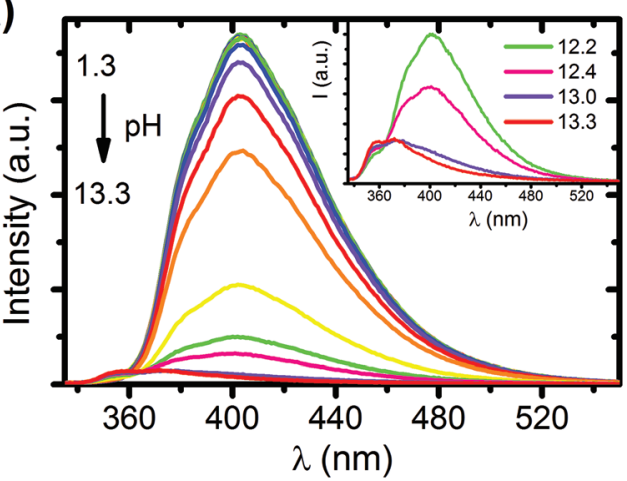

b)

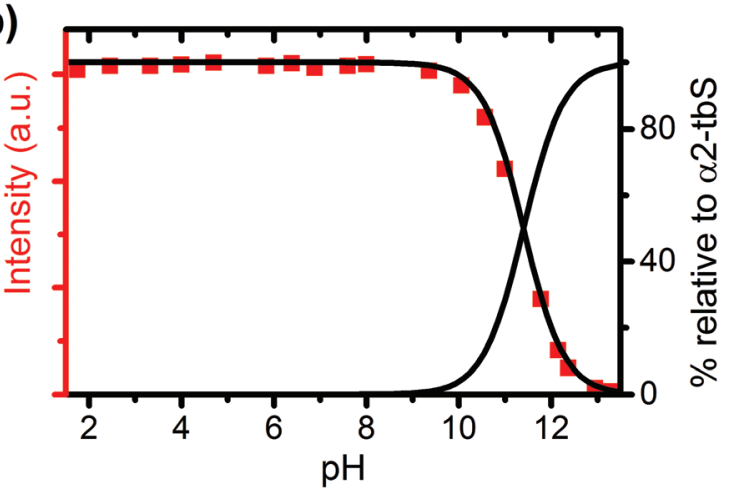

Fig. 4 (a) Steady-state fluorescence emission spectra of $\alpha 2$-tbS $\left(\lambda_{\text {exc }}=\right.$ $282 \mathrm{~nm}$ ) recorded at $T=298 \mathrm{~K}$ in water as a function of $\mathrm{pH}$. Inset: emission of fluorescence from $\mathrm{pH} 12.15$ to 13.29; and (b) emission of fluorescence at $402 \mathrm{~nm}(\square)$ and mole fraction distribution curves for the different protonated forms (solid lines).

Table 2 Photophysical data including fluorescence quantum yields $\left(\phi_{\mathrm{F}}\right)$, fluorescence lifetimes $\left(\tau_{\mathrm{F}}\right)$, and rate constants $\left(k_{\mathrm{F}}\right.$ and $\left.k_{\mathrm{NR}}\right)$ of $\alpha 2$-tbS obtained in water at different $\mathrm{pH}$ values and at $T=293 \mathrm{~K}$ with $\lambda_{\text {exc }}=$ $339 \mathrm{~nm}$ and $\lambda_{\mathrm{em}}=402 \mathrm{~nm}$ (decays). The chi-squared $\left(\chi^{2}\right)$ values resulting from the analysis of the fluorescence decays are also given as criteria to judge the quality of the fit

\begin{tabular}{llllll}
\hline $\mathrm{pH}$ & $\phi_{\mathrm{F}}$ & $\tau_{\mathrm{F}}(\mathrm{ns})$ & $\chi^{2}$ & $k_{\mathrm{F}}{ }^{a}\left(\mathrm{~ns}^{-1}\right)$ & $k_{\mathrm{NR}}{ }^{b}\left(\mathrm{~ns}^{-1}\right)$ \\
\hline 1.0 & $\mathrm{ND}$ & 0.45 & 1.07 & - & - \\
1.6 & 0.1 & 0.41 & 1.02 & 0.24 & 2.20 \\
3.6 & $\mathrm{ND}$ & 0.41 & 0.96 & - & - \\
7.1 & 0.1 & 0.41 & 1.04 & 0.24 & 2.20 \\
9.0 & 0.08 & 0.43 & 1.03 & 0.19 & 2.14 \\
10.8 & 0.08 & 0.45 & 1.13 & 0.18 & 2.04 \\
11.1 & $\mathrm{ND}$ & 0.45 & 0.98 & - & - \\
12.6 & 0.01 & 0.46 & 1.35 & 0.02 & 2.15
\end{tabular}

${ }^{a} k_{\mathrm{F}}=\frac{\phi_{\mathrm{F}}}{\tau_{\mathrm{F}}} \cdot{ }^{b} k_{\mathrm{NR}}=\frac{1-\phi_{\mathrm{F}}}{\tau_{\mathrm{F}}} . \mathrm{ND}=$ not determined. 
$\left(\phi_{\mathrm{F}}\right)$. With the addition of sulfonamide groups in the structure of bithiophene, a 10-fold increase in the value of the fluorescence quantum yield of $\boldsymbol{\alpha} 2$ (reported to be 0.01 in ethanol ${ }^{32}$ ) was achieved with values of $\phi_{\mathrm{F}} \sim 0.1$ in the $\mathrm{pH}$ range from 2.1 to 9.0; lower values of $\phi_{\mathrm{F}} \sim 0.01$ at $\mathrm{pH}=12.5$ show that the deprotonation of the sulfonamide groups allows them to quench the excited fluorophore by electron transfer. ${ }^{33}$

From the fluorescence emission titration, the excited state dissociation constant for the equilibrium between the neutral and deprotonated species was found to be $\mathrm{p} \beta_{13^{*}} \sim 11.4$ (see Fig. $4 \mathrm{~b}$ ), in good agreement with the value previously reported for sulfonamide derivatives and the one obtained from the spectroscopic titration. ${ }^{34}$

\section{Time-resolved fluorescence}

Time-resolved fluorescence measurements in water at different $\mathrm{pH}$ values and in organic solvents were obtained for $\boldsymbol{\alpha 2}$-tbS at $T=293 \mathrm{~K}$.

Table 2 summarizes the lifetime values, fluorescence quantum yield and rate radiative and radiationless rate constants of $\boldsymbol{\alpha 2}$-tbS at different $\mathrm{pH}$ values with the objective to rationalize the influence of the deprotonation of sulfonamide on the photophysics of the compound. The analysis of the data revealed that the fluorescence decays are always single exponential even when the deprotonation of the sulfonamide is reached where a double exponential could be anticipated due to the simultaneous presence of protonated and unprotonated species in the ground state (see Fig. S10†). This behavior indicates that despite the (ground state) deprotonation, the resulting excited state is a species that is independent of the solvent. This is further complemented by the consistency of the lifetime values with $\mathrm{pH}$ (Table 2) indicating the same excited state emissive species. However, the deprotonation of the sulfonamide is indeed affecting the fluorescence quantum yield since there is a decrease from 0.1 to 0.01 after the $p \beta_{3}$ is reached. This effect is further mirrored in the radiative rate constant, which decreases by one order of magnitude upon the increase in $\mathrm{pH}$ from 10.1 to 12.56 , whereas the radiationless rate constant remains approximately identical in value $\left(\sim 2 \mathrm{~ns}^{-1}\right)$.

The photophysical data were also obtained for $\boldsymbol{\alpha 2}$-tbS in solvents of different viscosity and polarity (Fig. S11†). The data is summarized in Table 3. Again, and similarly to what was found with $\boldsymbol{\alpha} 2$, the $\phi_{\mathrm{F}}$ and $\tau_{\mathrm{F}}$ values are insensitive to the media.

For $\boldsymbol{\alpha} 2$ in dioxane, the radiative and radiationless rate constants are found to be 0.37 and $21 \mathrm{~ns}^{-1}$. $^{32}$ Comparison with the data in Table 3 for $\boldsymbol{\alpha 2}$-tbS clearly shows a high decrease in the radiationless decay, pointing out for a much more efficient radiative channel with this derivative while keeping essentially the same spectroscopic characteristics. This paves the way for sensor applications of these compounds as demonstrated in the next section.

\section{Metal sensing ability}

The high solubility of the ligand $\boldsymbol{\alpha 2}$-tbS in water allowed further evaluating the feasibility of $\boldsymbol{\alpha 2}$-tbS as a fluorescent
Table 3 Fluorescence quantum yields $\left(\phi_{\mathrm{F}}\right)$, radiative $\left(k_{\mathrm{F}}\right)$, and radiationless $\left(k_{N R}\right)$ rate constants and fluorescence lifetimes $\left(\tau_{F}\right)$ of $\alpha 2$-tbS in different organic solvents and at $T=293 \mathrm{~K}$ obtained with $\lambda_{\text {exc }}=339 \mathrm{~nm}$ and $\lambda_{\mathrm{em}}=402 \mathrm{~nm}$. The chi-squared $\left(\chi^{2}\right)$ values resulting from the analysis of the fluorescence decays are also given as criteria to judge the quality of the fit

\begin{tabular}{llllll}
\hline Solvent & $\phi_{\mathrm{F}}$ & $\tau_{\mathrm{F}}(\mathrm{ns})$ & $\chi^{2}$ & $k_{\mathrm{F}}{ }^{a}\left(\mathrm{~ns}^{-1}\right)$ & $k_{\mathrm{NR}}{ }^{b}\left(\mathrm{~ns}^{-1}\right)$ \\
\hline Dioxane & 0.16 & 0.51 & 0.85 & 0.32 & 1.65 \\
DMF & 0.15 & 0.53 & 0.95 & 0.28 & 1.62 \\
$\mathrm{MeOH}$ & 0.12 & 0.39 & 1.06 & 0.30 & 2.30 \\
${ }^{a} k_{\mathrm{F}}=\frac{\phi_{\mathrm{F}}}{\tau_{\mathrm{F}}} \cdot{ }^{b} k_{\mathrm{NR}}=\frac{1-\phi_{\mathrm{F}}}{\tau_{\mathrm{F}}}$. & & &
\end{tabular}

sensor toward metal ions. Therefore, spectrofluorimetric titrations of $\boldsymbol{\alpha 2}$-tbS with $\mathrm{Cu}^{2+}, \mathrm{Co}^{2+}, \mathrm{Hg}^{+}, \mathrm{Hg}^{2+}, \mathrm{Cd}^{2+}, \mathrm{Pb}^{2+}, \mathrm{Mn}^{2+}$, and $\mathrm{Zn}^{2+}$ were performed. As shown before, the fluorescence of $\boldsymbol{\alpha 2}$-tbS is not $\mathrm{pH}$ sensitive until the deprotonation of the sulfonamide group occurs (Fig. 4); therefore, a wide range of $\mathrm{pH}$ values was used in the spectrofluorimetric titrations with the metal ions. The corresponding emission intensity at $402 \mathrm{~nm}$ for the whole $\mathrm{pH}$ range studied is included in ESI (see Fig. S12†). During the titrations with different metals, no significant changes in absorbance were observed. However, remarkable changes in the emission of fluorescence were observed with $\mathrm{Cu}^{2+}$ and $\mathrm{Hg}^{2+}$. In case of mercury and manganese, the hydrolysis equilibria could compete with binding reactions at basic $\mathrm{pH}$ values. Nevertheless, no recognition has been found for any species of these two metal ions.

Fig. 5 shows the changes in the emission intensity observed resulting from the interaction of $\boldsymbol{\alpha 2}$-tbS with the metal ions at $\mathrm{pH}=7.0$. From these results, the high selectivity of the system $\boldsymbol{\alpha 2}$-tbS for sensing $\mathrm{Cu}^{2+}$ cations in aqueous solution in a $\mathrm{pH}$ window around 7 should be highlighted. A strong CHEQ (chelation enhancement quenching) effect can be observed with

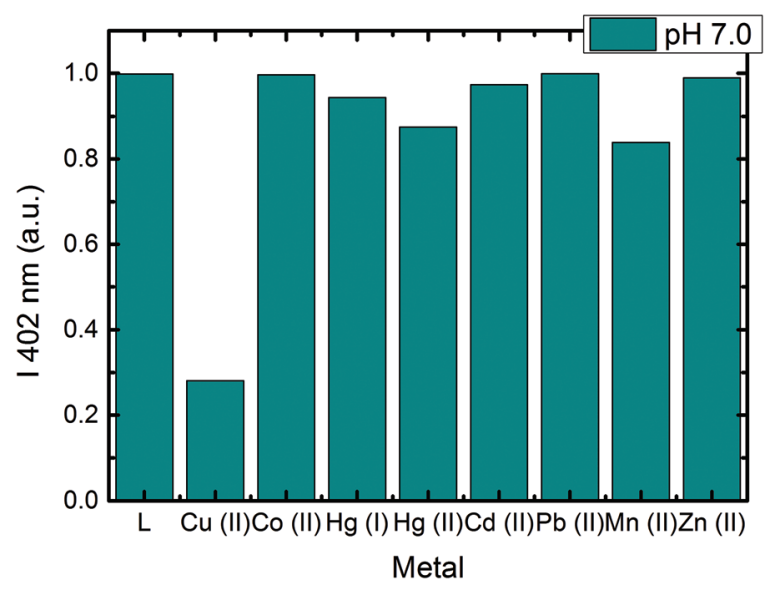

Fig. 5 Bar diagram representation of the normalized response fluorescence intensity of $\boldsymbol{\alpha} 2$-tbS upon the addition of divalent metal at $\mathrm{pH}$ 7.0. The $y$-axes have been constructed so that the fluorescence of the free ligand is normalized to 1 . Titrations performed in water $(\mathrm{pH}=7$, $[\boldsymbol{\alpha} 2-\mathrm{tbS}]=1.3 \times 10^{-5} \mathrm{M}$ ) at $T=298.1 \mathrm{~K}$ with $\lambda_{\text {exc }}=317 \mathrm{~nm}$. 


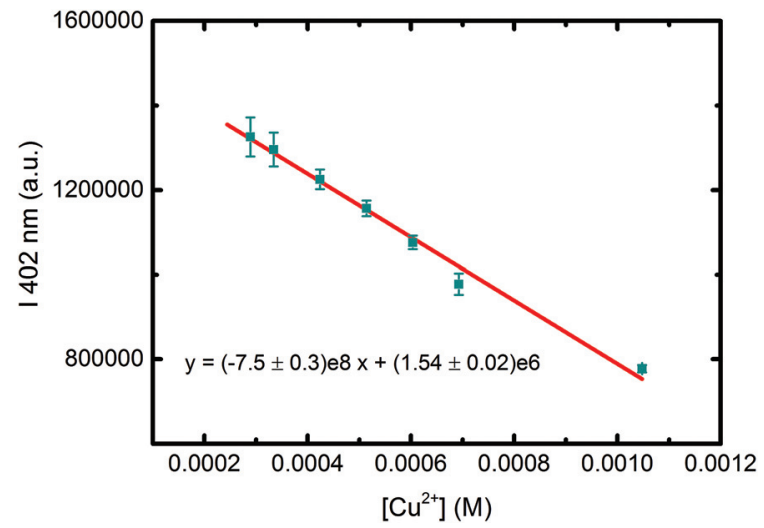

Fig. 6 Plot of the fluorescence intensity at $402 \mathrm{~nm}$ for $\alpha 2$-tbS vs. $\left[\mathrm{Cu}^{2+}\right]$ obtained at $\mathrm{pH}=7.5 .[\alpha 2-\mathrm{tbS}]=1.3 \times 10^{-5} \mathrm{M}, \lambda_{\mathrm{exc}}=317 \mathrm{~nm}$.

the copper complex formation that is allowed due to the deprotonation of the amide unit at this $\mathrm{pH}^{35,36}$ This quenching of the fluorescence is commonly observed in nitrogenated ligands containing aromatic fluorophores and is attributed to an energy transfer quenching of the $\pi, \pi^{*}$ emissive state (of the ligands) through low-lying metal-centered states. ${ }^{37}$

The behavior at other $\mathrm{pH}$ values was also evaluated in order to test $\boldsymbol{\alpha} 2$-tbS for metal recognition. The corresponding intensity variation at $\mathrm{pH} 7.6$ and 9.5 are shown in Fig. S13. $\dagger$ At higher $\mathrm{pH}$ values $\mathrm{Hg}^{2+}$-and in lower extent $\mathrm{Mn}^{2+}$-can be selectively recognized by $\boldsymbol{\alpha} 2$-tbS. In both cases, the metal recognition is achieved by the formation of a complex through the deprotonation of the amide, causing a decrease in the emission of the fluorescence. ${ }^{38,39}$

In addition to this high selectivity for $\mathrm{Cu}^{2+}$, a remarkable additional feature of this sensing system is its sensitivity. The detection limit depends on the instrumentation (i.e. the signal-to-noise ratio, SNR, gives a quantitative indication of the sensitivity of the equipment) and on the sensitivity of the ligand towards $\mathrm{Cu}^{2+}$, defined as the slope of $\mathrm{d}$ (luminescence)/ $\mathrm{d}$ [cation] (Fig. 6). Using these two parameters, the limit of detection can then be calculated as $3^{*} \mathrm{SNR} /$ (sensitivity of the ligand). The mean value of $0.64 \pm 0.02 \mathrm{ppm}$, with a linear range from $0.64 \mathrm{ppm}$ to $389 \mathrm{ppm}$, lies far below the value of $1.25 \mathrm{ppm}$, which is the maximum allowed value of $\mathrm{Cu}^{2+}$ amount in drinking water by the USA Environmental Protection Agency (EPA). ${ }^{15}$

\section{Experimental}

\section{Materials and methods}

The chemicals chlorosulfonic acid, sodium bicarbonate, and tert-butylamine were obtained from commercial sources and used as received. 2,2'-Bithiophene was purified by sublimation with a cold finger. Water was twice distilled and passed through a Millipore apparatus. All the solvents (spectroscopic or equivalent grade) were used without further purification. The $\mathrm{pH}$ values were measured with a 3510 Jenway $\mathrm{pH}$ meter and adjustments of the hydrogen ion concentration of the solutions were made with diluted $\mathrm{HClO}_{4}$ and $\mathrm{NaOH}$ solutions.

Perchlorate salts for $\mathrm{Cu}(\mathrm{II}), \mathrm{Zn}(\mathrm{II})$, and $\mathrm{Co}(\mathrm{II})$ solutions, sulphate salts for $\mathrm{Mn}$ (II), chloride salts for $\mathrm{Hg}$ (I) and $\mathrm{Hg}$ (II) and triflate salts for $\mathrm{Cd}$ (II) and $\mathrm{Pb}$ (II) were employed in the preparation of the solutions. The solutions of the ligand $\boldsymbol{\alpha} 2$-tbS were prepared by keeping the concentration equal to $1.3 \times 10^{-5} \mathrm{M}$.

Microwave-assisted synthesis was performed using a CEM Discover S-Class single-mode microwave reactor, featuring continuous temperature, pressure, and microwave power monitoring. ${ }^{1} \mathrm{H}$ NMR and ${ }^{13} \mathrm{C}$ NMR spectra were recorded using a Bruker-AMX with an operating frequency of 400 and $101 \mathrm{MHz}$, respectively. High-resolution mass spectrometry (HRMS) was performed using a Bruker microTOF-Focus mass spectrometer equipped with an electrospray ionization time-of-flight (ESI-ToF) source.

The absorption and fluorescence spectra were recorded with a Cary 5000 spectrophotometer and a Horiba-Fluoromax spectrofluorimeter, respectively. All the fluorescence spectra were corrected for the wavelength response of the system. The fluorescence quantum yields were measured using the absolute method with a Hamamatsu Quantaurus QY absolute photoluminescence quantum yield spectrometer model C11347 (integration sphere). The absorption of the solutions was kept under 0.1 at the excitation wavelength to avoid the inner filter effect. ${ }^{40}$ Fluorescence decay times were obtained using two (ps- and nstime resolution) Time-Correlated Single Photon Counting (TCSPC) technique with nanosecond time resolution using equipment described elsewhere. ${ }^{41,42}$ The obtained fluorescence decays were deconvoluted employing the method of modulating functions implemented by George Striker. ${ }^{43}$

\section{Synthetic procedures}

Synthesis [2,2'-bithiophene]-3,5,5'-trisulfonyltrichloride, $\alpha 2$ Cl. 2,2'-Bithiophene $(\boldsymbol{\alpha} 2)(0.6 \mathrm{~g}, 3.61 \mathrm{mmol})$ was placed in a round bottom flask under nitrogen in an ice-bath. Keeping an inert atmosphere, chlorosulfonic acid (13 $\mathrm{mL}, 180 \mathrm{mmol}$ ) was added. The mixture was stirred at $0{ }^{\circ} \mathrm{C}$ for 12 hours and then overnight at room temperature. The solution was neutralized with saturated $\mathrm{NaHCO}_{3}(\mathrm{aq})$ and the solid was then filtered and washed with water $(2.01 \mathrm{~g}, 82 \%$ yield (90\% purity by NMR)). ${ }^{1} \mathrm{H}$ NMR (DMSO, $400 \mathrm{MHz}$ ): $\delta$ (ppm), 7.04 (d, $J=3.7$ $\mathrm{Hz}, 1 \mathrm{H}$ ), 7.22 (s, 1H), 7.49 (d, $J=3.7 \mathrm{~Hz}, 1 \mathrm{H}) .{ }^{13} \mathrm{C}$ NMR (DMSO, $101 \mathrm{MHz}): \delta$ (ppm), 126.4, 128.1, 129.3, 132.3, 134.3, 142.9, 146.4, 151.0.

Synthesis $N^{3}, N^{5}, N^{5^{\prime}}$-tri-tert-butyl-[2,2'-bithiophene]-3,5,5'-trisulfonamide, $\boldsymbol{\alpha} 2$-tbS. The chlorosulfonic intermediate $\boldsymbol{\alpha} \mathbf{2}$-Cl (0.52 g, $1.01 \mathrm{mmol}$ ) was dissolved in dichloromethane $(2 \mathrm{~mL})$. Then, tert-butylamine $(331.7 \mu \mathrm{L}, 3.16 \mathrm{mmol})$ and triethylamine (440.6 $\mu \mathrm{L}, 3.16 \mathrm{mmol}$ ) were added. The reaction was carried out under microwave conditions at $60{ }^{\circ} \mathrm{C}$ for $25 \mathrm{~min}$. The solvent was removed under vacuum. To the reaction crude, $50 \mathrm{~mL}$ of water was added and the organic compounds were with $\mathrm{CH}_{2} \mathrm{Cl}_{2}(3 \times 40 \mathrm{~mL})$. The combined organic phases were dried over $\mathrm{Na}_{2} \mathrm{SO}_{4}$, filtered and evaporated to dryness. The residue was purified through $\mathrm{SiO}_{2}$ column chromatography 
using as eluent $\mathrm{CH}_{2} \mathrm{Cl}_{2}$ : acetone $(80: 20)$ to obtain the desired compound $\boldsymbol{\alpha 2}$-tbS in $70 \%$ yield. ${ }^{1} \mathrm{H}$ NMR $\left(\mathrm{CDCl}_{3}, 400 \mathrm{MHz}\right): \delta$ (ppm), 1.31-1.32 (m, 27H), 4.99 (s, 1H), 5.17 (s, 1H), 7.50 (d, $J$ $=3.9 \mathrm{~Hz}, 1 \mathrm{H}), 7.65(\mathrm{~d}, J=3.9 \mathrm{~Hz}, 1 \mathrm{H}), 7.95(\mathrm{~s}, 1 \mathrm{H}) .{ }^{13} \mathrm{C} \mathrm{NMR}$ (CDCl3, $101 \mathrm{MHz}): \delta$ (ppm), 30.1, 129.6, 131.6, 133.9, 137.8, 138.1, 142.0, 142.1, 147. ESI-MS $(\mathrm{m} / \mathrm{z})$ : calculated for $\mathrm{C}_{20} \mathrm{H}_{33} \mathrm{~N}_{3} \mathrm{O}_{6} \mathrm{~S}_{5}$ : 571.0973; found: $[\mathrm{L}+\mathrm{H}]^{+} 572.1046$

\section{Conclusions}

The study undertaken paves the way to the discovery of structural requirements for the synthesis of new water-soluble bithiophenes, with a strong increment in fluorescent efficiency and selectivity towards metal ions. The solubility of $\boldsymbol{\alpha 2}$-tbS in water enabled its application as a selective sensor for copper and mercury in aqueous solutions, in a wide range of $\mathrm{pH}$ values. The low detection limit obtained for copper in pure water showed that sulfonamide bithiophene derivatives have a very promising application in the detection of $\mathrm{Cu}^{2+}$. Moreover, the increase in the fluorescence quantum yield (also valid for the fluorescence lifetime) on going from $\alpha 2$ to $\alpha 2$-tbS is the key to the design and subsequent preparation of highly fluorescent oligothiophenes for potential use as functional materials.

\section{Conflicts of interest}

There are no conflicts to declare.

\section{Acknowledgements}

This work was supported by Project "Hylight" (no. 031625) 02/SAICT/2017, PTDC/QUI-QFI/31625/2017, which is funded by the Portuguese Science Foundation (Fundação para Ciência e Tecnologia, FCT) and Compete Centro 2020, project "SunStorage-Harvesting and storage of solar energy", reference POCI-01-0145-FEDER-016387, funded by the European Regional Development Fund (ERDF), through COMPETE 2020-Operational Programme for Competitiveness and Internationalization (OPCI), and by national funds, through FCT. We acknowledge the funding by Fundo Europeu de Desenvolvimento Regional (FEDER) through Programa Operacional Factores de Competitividade (COMPETE). The Coimbra Chemistry Centre is supported by FCT, through Projects IDB/00313/2020 and UIDP/00313/2020. The research leading to these results has received funding from LaserlabEurope (grant agreement no. 284464, EC's Seventh Framework Programme). E. D-P thanks Laserlab Portugal (LLPT) (ref: CENTRO-01-0145-FEDER-000014) for a post-doctoral grant (project no. 22124).

\section{Notes and references}

1 K. P. Carter, A. M. Young and A. E. Palmer, Chem. Rev., 2014, 114, 4564-4601.
2 K. Nienhaus and G. Ulrich Nienhaus, Chem. Soc. Rev., 2014, 43, 1088-1106.

3 B. Liu and G. C. Bazan, Chem. Mater., 2004, 16, 44674476.

4 R. D. McCullough, Handbook of Oligo- and Polythiophenes, 1998, ch. 1, pp. 1-44, DOI: 10.1002/9783527611713.ch1.

5 K. P. R. Nilsson and O. Inganäs, Nat. Mater., 2003, 2, 419424.

6 L. Chen, D. W. McBranch, H.-L. Wang, R. Helgeson, F. Wudl and D. G. Whitten, Proc. Natl. Acad. Sci. U. S. A., 1999, 96, 12287.

7 R. D. McCullough, The Chemistry of Conducting Polythiophenes: from Synthesis to Self-Assembly to Intelligent Materials, Wiley, 2008.

8 Handbook of Thiophene-Based Materials: Applications in Organic Electronics and Photonics, Wiley, 2009.

9 D. T. Quang and J. S. Kim, Chem. Rev., 2010, 110, 62806301.

10 A. Rani, A. Kumar, A. Lal and M. Pant, Int. J. Environ. Health Res., 2014, 24, 378-399.

11 G. Flora, D. Gupta and A. Tiwari, Interdiscip. Toxicol., 2012, $5,47-58$.

12 J. J. A. Cotruvo, A. T. Aron, K. M. Ramos-Torres and C. J. Chang, Chem. Soc. Rev., 2015, 44, 4400-4414.

13 I. F. Scheiber, J. F. B. Mercer and R. Dringen, Prog. Neurobiol., 2014, 116, 33-57.

14 E. Tiffany-Castiglioni, S. Hong and Y. Qian, Int. J. Dev. Neurosci., 2011, 29, 811-818.

15 U. S. EPA, Fed. Regist., 1991, 56, 5.

16 J. S. Seixas de Melo, F. Elisei, C. Gartner, G. G. Aloisi and R. S. Becker, J. Phys. Chem. A, 2000, 104, 6907-6911.

17 Y. Miyata, T. Nishinaga and K. Komatsu, J. Org. Chem., 2005, 70, 1147-1153.

18 P. Díaz, A. Doménech, E. García-España and C. Soriano, Polyhedron, 2002, 21, 1523-1530.

19 S. Das, D. P. Chatterjee, R. Ghosh and A. K. Nandi, RSC Adv., 2015, 5, 20160-20177.

20 S. Zhang, Q. Niu, L. Lan and T. Li, Sens. Actuators, B, 2017, 240, 793-800.

21 M. A. Ismail, S. A. E. Bialy, R. Brun, T. Wenzler, R. Nanjunda, W. D. Wilson and D. W. Boykin, Bioorg. Med. Chem., 2011, 19, 978-984.

22 D. G. J. Batista, M. G. O. Pacheco, A. Kumar, D. Branowska, M. A. Ismail, L. Hu, D. W. Boykin and M. N. C. Soeiro, Parasitology, 2009, 137, 251-259.

23 R. Nhili, P. Peixoto, S. Depauw, S. Flajollet, X. Dezitter, M. M. Munde, M. A. Ismail, A. Kumar, A. A. Farahat, C. E. Stephens, M. Duterque-Coquillaud, W. David Wilson, D. W. Boykin and M.-H. David-Cordonnier, Nucleic Acids Res., 2012, 41, 125-138.

24 D. N. Kaluzhny, O. F. Borisova and A. K. Shchyolkina, Biopolymers, 2010, 93, 8-20.

25 C. A. Fink, J. M. McKenna and L. H. Werner, Diuretic and uricosuric agents, John Wiley \& Sons, New York, 2003.

26 R. C. Pereira, M. Pineiro, A. M. Galvão and J. S. Seixas de Melo, Dyes Pigm., 2018, 158, 259-266. 
27 R. C. Pereira, A. D. R. Pontinha, M. Pineiro and J. S. Seixas de Melo, Dyes Pigm., 2019, 166, 203-210.

28 R. M. Kellogg, A. P. Schaap and H. Wynberg, J. Org. Chem., 1969, 34, 343-346.

29 I. Novak, S. C. Ng, H. H. Huang, C. Y. Mok, E. Khor and B. Kovač, J. Phys. Org. Chem., 1991, 4, 675-680.

30 A. Almenningen, O. Bastiansen and P. Svendsås, Acta Chem. Scand., 1958, 12, 3.

31 B. A. Caine, M. Bronzato and P. L. A. Popelier, Chem. Sci., 2019, 10, 6368-6381.

32 R. S. Becker, J. S. Seixas de Melo, A. L. Maçanita and F. Elisei, J. Phys. Chem., 1996, 100, 18683-18695.

33 F. Pina, J. C. Lima, C. Lodeiro, J. S. Seixas de Melo, P. Díaz, M. T. Albelda and E. García-España, J. Phys. Chem. A, 2002, 106, 8207-8212.

34 T. Koike, E. Kimura, I. Nakamura, Y. Hashimoto and M. Shiro, J. Am. Chem. Soc., 1992, 114, 7338-7345.

35 H. Sigel and R. B. Martin, Chem. Rev., 1982, 82, 385-426.

36 H.-J. Liu, Y.-H. Hung, C.-C. Chou and C.-C. Su, Chem. Commun., 2007, 495-497, DOI: 10.1039/B613583H.
37 R. Aucejo, J. Alarcón, E. García-España, J. M. Llinares, K. L. Marchin, C. Soriano, C. Lodeiro, M. A. Bernardo, F. Pina, J. Pina and J. Seixas de Melo, Eur. J. Inorg. Chem., 2005, 2005, 4301-4308.

38 S. Syed Shoaib Ahmad, A. Muhammad, N. Tayyaba, A. Muhammad Mehboob, S. Salma, T. Rukhsana and E. Syeda Abida, Curr. Bioact. Compd., 2013, 9, 211220.

39 M. Pervaiz, A. Riaz, A. Munir, Z. Saeed, S. Hussain, A. Rashid, U. Younas and A. Adnan, J. Mol. Struct., 2020, $1202,127284$.

40 D. Magde, R. Wong and P. G. Seybold, Photochem. Photobiol., 2002, 75, 327-334.

41 A. L. Maçanita, F. P. Costa, S. M. B. Costa, E. C. Melo and H. Santos, J. Phys. Chem., 1989, 93, 336.

42 J. Pina, J. S. Seixas de Melo, H. D. Burrows, A. L. Maçanita, F. Galbrecht, T. Bunnagel and U. Scherf, Macromolecules, 2009, 42, 1710-1719.

43 G. Striker, V. Subramaniam, C. A. M. Seidel and A. Volkmer, J. Phys. Chem. B, 1999, 103, 8612. 